\title{
Effects of Organic Compounds on Microstructure, Optical, and Electrical Properties of ITO Thin Films Prepared by Dip-Coating Method
}

\author{
Ru-Yuan Yang, ${ }^{1}$ Cheng-Jye Chu, ${ }^{2}$ Yu-Ming Peng, ${ }^{1}$ and Hui-Ju Chueng ${ }^{2}$ \\ ${ }^{1}$ Department of Material Engineering, National Pingtung University of Science and Technology, Pingtung County 912, Taiwan \\ ${ }^{2}$ Nanmat Technology CO., Ltd., Kaohsiung 811, Taiwan
}

Correspondence should be addressed to Ru-Yuan Yang, ryyang@mail.npust.edu.tw

Received 21 May 2012; Accepted 3 August 2012

Academic Editor: Yu-Pei Huang

Copyright () 2012 Ru-Yuan Yang et al. This is an open access article distributed under the Creative Commons Attribution License, which permits unrestricted use, distribution, and reproduction in any medium, provided the original work is properly cited.

Tin-doped Indium oxide (ITO) thin films were prepared by sol-gel dip-coating technique using low-cost metal salts and organic solvents. The coated films were treated without annealing or annealed at $400^{\circ} \mathrm{C}$ and $600^{\circ} \mathrm{C}$ in $3 \% \mathrm{H}_{2} / 97 \% \mathrm{~N}_{2}$ mixtures atmosphere. Microstructure, optical, and electrical properties of the prepared ITO films were investigated in detail. The maximum transmittance in the visible range $(380-780 \mathrm{~nm})$ is $85.6 \%$, and the best resistivity is $5 \times 10^{-2} \Omega$ - $\mathrm{cm}$ when annealed at $600^{\circ} \mathrm{C}$ in $3 \% \mathrm{H}_{2} / 97 \% \mathrm{~N}_{2}$ mixtures atmosphere. It is found that the optical and electrical properties of the prepared ITO films are strongly related to the microstructure variation. The organic compounds could not be removed completely, and the prepared ITO thin films were not dense when the prepared ITO film was annealed at $600^{\circ} \mathrm{C}$ in $3 \% \mathrm{H}_{2} / 97 \% \mathrm{~N}_{2}$ mixtures atmosphere, causing the poor conductivity.

\section{Introduction}

Tin-doped Indium oxide (ITO) thin films have been widely applied in touch panel contacts, electrodes for LCD and electrochromic displays, gas sensors, heat-reflecting coatings to increase light bulb efficiency, antistatic window coatings, energy conserving architectural windows and so on [1-4]. A variety of fabricating methods have been employed to prepare the ITO thin films, such as sputtering [5], chemical vapor deposition [6], and sol-gel process [7]. Among the variously available kinds of techniques, the sol-gel technique seemed to attract much attention for its advantages such as simplicity, low cost, doping levels easily controlled and feasible preparation for large area films and without using expensive and complex equipments. Moreover, process conditions affect the densification and crystallization of the ITO films prepared by the sol-gel technique. However, the ITO films prepared by sol-gel technique exhibit a relatively low conductivity resulting from considerable porosity even after films with postannealed at a high temperature and the difficulty to obtain metal alkoxides as raw materials for their unavailability and high price [8-10].

In this paper, the ITO thin films were prepared by sol-gel dip-coating technique using low-cost metal salts and organic solvents. The effects of postannealing temperature in $3 \%$ $\mathrm{H}_{2} / 97 \% \mathrm{~N}_{2}$ mixtures atmosphere on morphology, structure, and electrical properties of the ITO thin films are investigated to verify the relationship between the process condition and the properties of the prepared films. It is found that the optical and electrical properties of the prepared ITO films are strongly related to the microstructure variation, especially resulted from the organic compounds of the precursors.

\section{Experimental}

Figure 1 shows a diagram of the synthesis and deposition process of the prepared ITO films coating on glass substrate in detail. First, anhydrous indium chloride $\left(\mathrm{InCl}_{3}\right)$ was dissolved in isopropyl alcohol in the mix after adding 


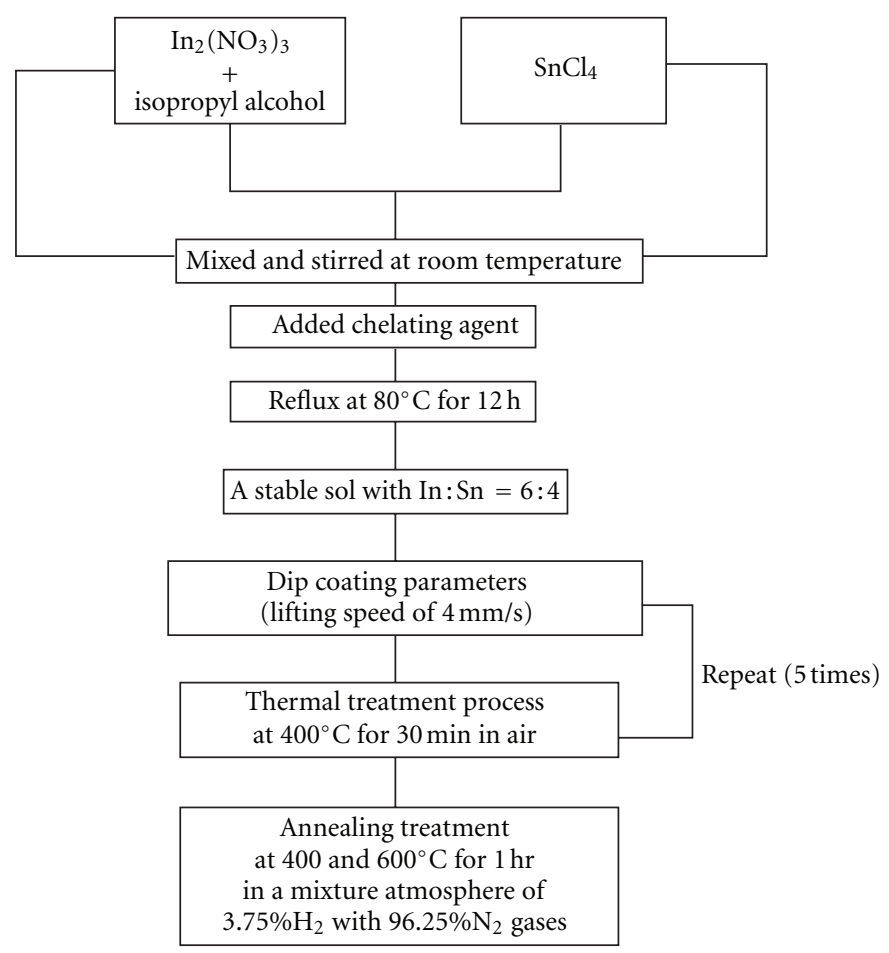

FIGURE 1: A diagram of the synthesis and deposition process of the prepared ITO films coating on glass substrate.

anhydrous tin chemical compound $\left(\mathrm{SnCl}_{4}\right)$ and stirred at room temperature. Secondary, chelating agent added to the solution and maintained in reflux at $80^{\circ} \mathrm{C}$ for $12 \mathrm{~h}$. Finally, a stable sol with the molar ratio of the $I n: S n=6: 4$ was obtained. Additionally, the cleaned glass plates $(20 \mathrm{~mm} \times$ $20 \mathrm{~mm} \times 3 \mathrm{~mm}$ ) were used as the substrates for coating. The sol containing In and Sn sources was prepared on the glass substrate by dip-coating method at a withdrew speed of $4 \mathrm{~mm} / \mathrm{sec}$. Then, the film was fired at $400^{\circ} \mathrm{C}$ for $30 \mathrm{~min}$ in air and then cooled down to room temperature. A completely deposition involved 5 orders of the dipping and firing process to form the as-prepared ITO thin films. The total thickness of the as-prepared ITO films was controlled in the range of 250 to $300 \mathrm{~nm}$. Finally, the as-prepared ITO films were annealed in $3 \% \mathrm{H}_{2} / 97 \% \mathrm{~N}_{2}$ mixtures atmosphere in a tube furnace at 400 and $600^{\circ} \mathrm{C}$ for $1 \mathrm{hr}$.

Thermogravimetric-differential thermal analysis (TGDTA 2000, MAC Science Co., Ltd., Japan) was used to obtain the weight loss and reaction behavior of the gel and performed under the atmospheric air condition with a heating rate of $5^{\circ} \mathrm{C} / \mathrm{min}$. X-ray diffraction system (XRD, BRUKER D8 ADVANCE) equipped with $\mathrm{CuK}_{\alpha}$ radiation of average wavelength $1.5406 \AA$ was used to specify the existent phases and the orientation of the ITO thin films. X-ray patterns were taken $2 \theta$ between $20^{\circ}$ and $80^{\circ}$ and scan speed of $4.5^{\circ} / \mathrm{min}$. Fourier Transform Infrared Spectroscopy (FTIR, Spectrum 100) and Energy Dispersive Spectrometer (EDS, JSM-6400F. JEOL, Japan) were used to detect the residue of the organic compounds in the ITO thin films, wherein the FTIR spectra were recorded at the range of $4000 \mathrm{~cm}^{-1}$ to $400 \mathrm{~cm}^{-1}$ [11]. Field emission-scanning electron microscopy (FE-SEM, JSM-6400F. JEOL, Japan) and Atomic force microscopy (AFM, Veeco CP series) were used to observe the surface microstructure morphologies of the ITO thin films. Moreover, the standard four-point probe method was used to measure the room-temperature conductivity of the ITO thin films.

\section{Results and Discussion}

Figure 2 shows the TG-DTA curves of the ITO gel. The weight mass of ITO gel displays continuous and significant decrease with the rising of heat treatment temperature before $361^{\circ} \mathrm{C}$. There are four endothermic peaks at $65,94,213$, and $279^{\circ} \mathrm{C}$, respectively, and one distinct exothermic peak at $361^{\circ} \mathrm{C}$. The endothermic peaks are attributed to heat release from charring and decomposition of organic groups and components, and the exothermic peak is proposed resulting from the transformation of $\operatorname{In}_{2} \mathrm{O}_{3}$ to polycrystalline cubic bixbyite structure. In addition, the mass of ITO gel does not change at the temperature higher than $350^{\circ} \mathrm{C}$. Therefore, the temperature above $400^{\circ} \mathrm{C}$ was selected as firing temperature to prepare the desired ITO thin films in this work.

Figure 3 shows the XRD patterns of the ITO thin films treated without annealing, and with annealing at $400^{\circ} \mathrm{C}$ and $600^{\circ} \mathrm{C}$ in $3 \% \mathrm{H}_{2} / 97 \% \mathrm{~N}_{2}$ mixtures atmosphere. The major diffraction peaks angle of the $\mathrm{In}_{2} \mathrm{O}_{3}$ crystal located at $21.493^{\circ}, 30.579^{\circ}, 35.455^{\circ}$, and $51.013^{\circ}$ are corresponding to the reflection planes of (222), (400), (440), and (622), respectively, described in JCPDS database (Card No. 441087), which indicates that $\mathrm{In}_{2} \mathrm{O}_{3}$ phase is in a cubic system with the space group, $T_{h}^{7}$ Ia 3 , and lattice parameter, 


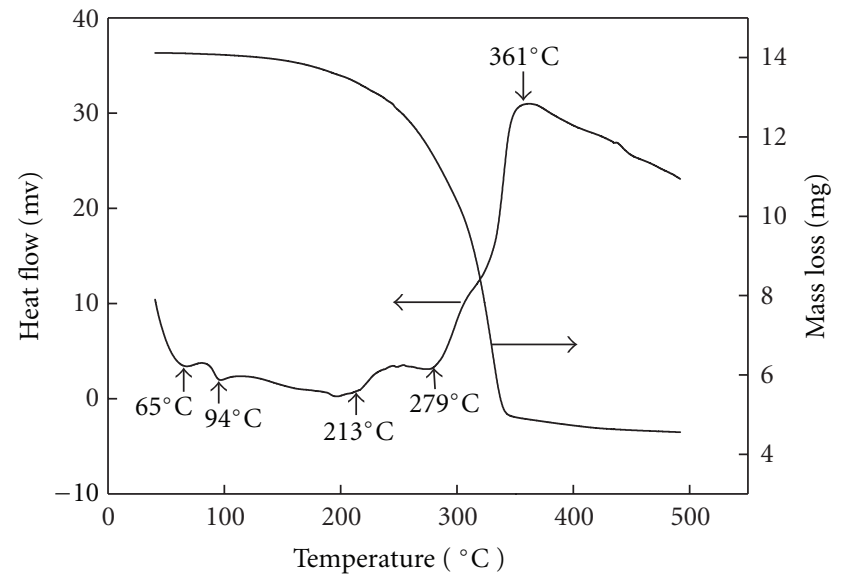

Figure 2: TG-DTA curves of the ITO gel.

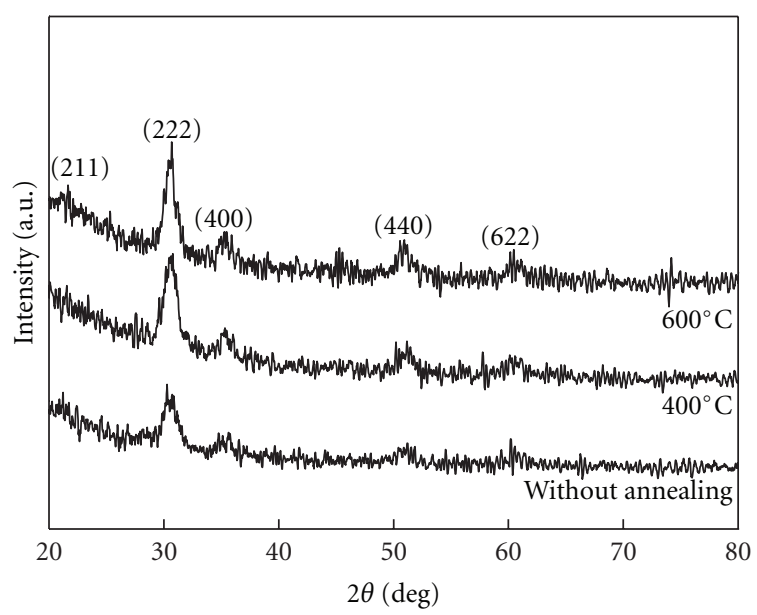

FIGURE 3: XRD patterns of the ITO thin films treated without annealing and with annealing at $400^{\circ} \mathrm{C}$ and $600^{\circ} \mathrm{C}$ in $3 \% \mathrm{H}_{2} / 97 \%$ $\mathrm{N}_{2}$ mixtures atmosphere.

$a=1.0117 \mathrm{~nm}$ at $26^{\circ} \mathrm{C}$ [12]. The spectrums show that the diffraction peaks of the ITO thin films treated without annealing are not obvious on the planes of the (400), (440), and (622) of the $\operatorname{In}_{2} \mathrm{O}_{3}$ crystal. When the ITO films treated with annealing temperature of $400^{\circ} \mathrm{C}$, the ITO gel gradually began to lose the intermolecular water and revealed the characteristic diffraction peaks of the $\operatorname{In}_{2} \mathrm{O}_{3}$ crystal $[9,10]$. All the diffraction peaks were weak even when the annealing temperature further was increased to $600^{\circ} \mathrm{C}$. In addition, no second phases corresponded to the other Sn compounds were found indicating that the Sn element was dissolved in the $\mathrm{In}_{2} \mathrm{O}_{3}$ to form a good solid solution. In ITO material system, Tin ion is tetravalent and Indium ion is trivalent, each $\mathrm{Sn}^{4+}$ replacing $\mathrm{In}^{3+}$ substitutionally, thus, contributing a free carrier electron for the conductivity. Therefore, the ITO thin films retain the cubic $\operatorname{In}_{2} \mathrm{O}_{3}$ structure up to the solid solubility limit of the $\mathrm{Sn}$ in the $\mathrm{In}_{2} \mathrm{O}_{3}$ [13]. However, not all the Sn atoms can be substituted to In atom sites. Therefore, small amounts of Sn(IV) may be transformed to Sn(II) [14]. When the annealing temperature was increased,

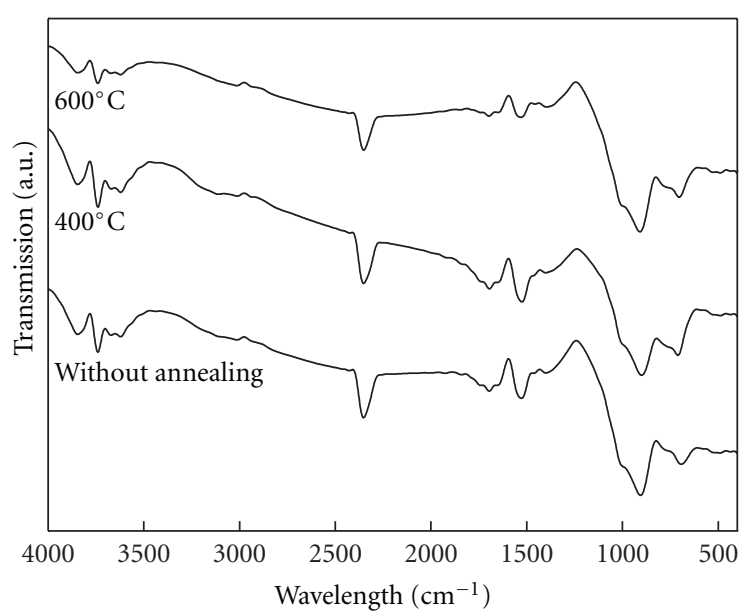

FIGURE 4: FTIR spectra of the ITO thin films treated without annealing and with annealing at $400^{\circ} \mathrm{C}$ and $600^{\circ} \mathrm{C}$ in $3 \% \mathrm{H}_{2} / 97 \%$ $\mathrm{N}_{2}$ mixtures atmosphere.

the width of the (222) diffraction peaks became more sharp due to the improved crystalline with increasing the postannealing temperature. The crystallinity of the ITO thin films can be improved by increasing the postannealing temperature [15]. Additionally, the crystallinity depends on the annealing temperatures rather than the atmosphere used in the postannealing process [5].

The average crystalline size $(D)$ of the ITO thin films is determined by applying the Scherrer equation to the full width at half maximum (FWHM) of the (222) diffraction peaks, as given by [16]

$$
D=\frac{0.9 \lambda}{\omega \cos \theta}
$$

where $\omega$ is the calibrated FWHM of the selected diffraction line in radians, $\theta$ is the Bragg angle, and $\lambda$ is the $\mathrm{X}$ ray wavelength $(0.15406 \mathrm{~nm})$. In Table 1 , the FWHM of (222) diffraction peaks were decreased with an increase in annealing temperature. Thus, the crystalline size was increased from about 3.3 to $4.5 \mathrm{~nm}$ for that treated without annealing to that treated with annealing temperature of $600^{\circ} \mathrm{C}$, indicating the crystalline of the ITO films can be improved with increasing annealing temperature [15].

Figure 4 shows the FTIR spectra of the ITO thin films treated without annealing and with annealing at $400^{\circ} \mathrm{C}$ and $600{ }^{\circ} \mathrm{C}$ in $3 \% \mathrm{H}_{2} / 97 \% \mathrm{~N}_{2}$ mixtures atmosphere. The bands appearing at below $900 \mathrm{~cm}^{-1}$ are corresponded to the stretching vibrations of In-O and $\mathrm{Sn}-\mathrm{O}$, as well as to the contributions of $\mathrm{In}=\mathrm{O}$ and $\mathrm{Sn}=\mathrm{O}$ bonds [9]. Moreover, there are a stretching vibration peak of $\mathrm{C}-\mathrm{C}$ band in the range $1652-1579 \mathrm{~cm}^{-1}$, a stretching vibration peak of $\mathrm{C}=\mathrm{O}$ band in the range $1727-1720 \mathrm{~cm}^{-1}$, and a stretching vibration peak of $\mathrm{C}-\mathrm{H}$ band in the range $2800-2200 \mathrm{~cm}^{-1}$ since the ITO thin films were treated without annealing. When the ITO thin films were treated without annealing and with annealing temperature at $400^{\circ} \mathrm{C}$, the FTIR characteristics almost do not change. However, when the ITO thin films were treated with annealing at $600^{\circ} \mathrm{C}$, the $\mathrm{C}-\mathrm{C}$ band, 
TABLE 1: Main characteristics of the prepared ITO thin films.

\begin{tabular}{|c|c|c|c|c|}
\hline Annealing conditions & Carbon content $\mathrm{t}^{\mathrm{a}}$ (weight $\%$ ) & FWHM $^{\mathrm{b}}$ (Degree) & Crystal size $(\mathrm{nm})$ & Conductivity $^{\mathrm{c}}(\mathrm{S} / \mathrm{cm})$ \\
\hline Without annealing & 8.15 & 2.5 & 3.3 & $0.3 \times 10^{1}$ \\
\hline Annealed at $400^{\circ} \mathrm{C}$ & 4.90 & 2.3 & 3.9 & $0.8 \times 10^{1}$ \\
\hline Annealed at $600^{\circ} \mathrm{C}$ & 0.00 & 1.9 & 4.5 & $2 \times 10^{1}$ \\
\hline
\end{tabular}

$\mathrm{C}=\mathrm{O}$ band and $\mathrm{C}-\mathrm{H}$ band, became broader. This result is due to the decreased organic compounds as increasing the annealing temperature $[10,11]$. Furthermore, under annealing treatment at a certain temperature, thin films are formed after withdrawing and drying to lose their intermolecular water and organic components gradually, and translated into crystalline state [11]. In Table 1, the residues of carbon from the organic compounds detected by EDS were decreased with increased annealing temperature. As annealing temperature was reached to $600^{\circ} \mathrm{C}$, carbon contents disappeared completely. Compare to the result from FTIR analysis, the organic compounds did not be decreased completely even as annealing temperature was reached to $600^{\circ} \mathrm{C}$. These results may be attributed to the detection limit of the EDS analyzer. Although the burned out temperature of the organic compounds is around $350^{\circ} \mathrm{C}$ which is obtained from the DTA/TG curve, the organic compounds were not decomposed completely as the ITO films were fired at $400^{\circ} \mathrm{C}$. The reason may be the holding time on the firing temperature is not enough to volatilize the organic compounds absolutely.

Figure 5 shows the SEM images of the ITO thin films treated without annealing, and with annealing at $400^{\circ} \mathrm{C}$ and $600^{\circ} \mathrm{C}$ in $3 \% \mathrm{H}_{2} / 97 \% \mathrm{~N}_{2}$ mixtures atmosphere. The prepared ITO thin films have a structure with full of cracks uniformly distributed such as [11]. All the SEM figures showed the presence of cracks, indicating the ITO thin films were not dense. The considerable porosity $(P \sim 51 \%)$ of the ITO thin films by using sol-gel method would not be removed even after annealing at a high temperature as the crystalline nanoparticle suspensions consists of an agglomeration of such particles [17]. Figures 5(a) and 5(b) show the average surface grain size of about 30.1 and $32.0 \mathrm{~nm}$ for the ITO films without annealing and with annealing at $400^{\circ} \mathrm{C}$ in $3 \% \mathrm{H}_{2} / 97 \% \mathrm{~N}_{2}$ mixtures atmosphere, respectively. However, there are almost no significant changes in the morphology as the annealing temperature was further increased to $600^{\circ} \mathrm{C}$, and the average surface grain size is about $32.3 \mathrm{~nm}$.

Figure 6 shows the AFM surface views (Scanning range: $\left.10 \times 10 \mu \mathrm{m}^{2}\right)$ of the ITO thin films treated without annealing, and with annealing at $400^{\circ} \mathrm{C}$ and $600^{\circ} \mathrm{C}$ in $3 \% \mathrm{H}_{2} / 97 \%$ $\mathrm{N}_{2}$ mixtures atmosphere. The average surface grain size and root-mean-square (RMS) roughness were high with an increased annealing temperature. This result was associated with the tendency of the grain growth by fusing adjacent grains when sufficient energy for surface rearrangement is provided by annealing. Larger grains are associated with higher RMS roughness [18]. In our work, RMS roughness and the average surface grain size were increased with the increased annealing temperature in the range from 2.0 to $4.8 \mathrm{~nm}$, and 30.1 to $32.3 \mathrm{~nm}$, for the ITO films without annealing and with annealing at $600^{\circ} \mathrm{C}$ in $3 \% \mathrm{H}_{2} / 97 \% \mathrm{~N}_{2}$ mixtures atmosphere, respectively. The morphology of the prepared ITO thin films depended substantially on annealing temperature [19].

The average grain size from SEM data was significantly larger than the average crystallite size in the film bulk derived from the FWHM of the (222) diffraction peaks and the RMS roughness from the AFM results [20]. The significant difference between the average crystallite and grain size was determined from XRD and AFM measurement; the reason was due to the fact that the AFM measurement was more sensitive to the surface structure and that of the XRD measurement was sensitive to the structure of the film bulk. Thus, the columns grown during the deposition tend to have larger diameter at the surface, resulting in larger surface grains than average grain size in the film bulk [21].

Figure 7 displays the optical transmittance spectra of the ITO thin films treated without annealing and with annealing at $400^{\circ} \mathrm{C}$ and $600^{\circ} \mathrm{C}$ in $3 \% \mathrm{H}_{2} / 97 \% \mathrm{~N}_{2}$ mixtures atmosphere. The maximum transmittance in the visible range (380$780 \mathrm{~nm})$ is $85.6 \%$ when the ITO films annealed at $600^{\circ} \mathrm{C}$ and approximately $74.6 \%$ and $81.4 \%$ for the films treated without annealing and annealed at $500^{\circ} \mathrm{C}$, respectively. The results agreed with those reported by Alam and Cameron They pointed out that the transmission in the visible range wavelengths was enhanced with increasing the annealing temperature due to crystallization and organic quantity [5].

As shown in Table 1, the conductivity of the prepared ITO films was in the range of $0.3 \times 10^{1}$ to $2 \times 10^{1} \mathrm{~S} / \mathrm{cm}$ for films without annealing, and with annealing at $400^{\circ} \mathrm{C}$ and $600^{\circ} \mathrm{C}$ in $3 \% \mathrm{H}_{2} / 97 \% \mathrm{~N}_{2}$ mixtures atmosphere. Since the resistivity is inverse to the conductivity, the resistivity of the prepared ITO films was in the range around $3 \times$ $10^{-1}$ to $5 \times 10^{-2} \Omega-\mathrm{cm}$. Actually, the conductivity of the ITO thin films is mainly derived from the donor-doping effect generated though replacement of In ion sites by Sn ions in lattice and the oxygen vacancy caused by annealing process. When $\mathrm{In}_{2} \mathrm{O}_{3}$ is doped by $\mathrm{Sn}$ ions, due to approximate radii between $\mathrm{In}^{3+}$ and $\mathrm{Sn}^{4+}, \mathrm{In}^{3+}$ ions site is easily replaced by $\mathrm{Sn}^{4+}$ ions site. The doping reaction can be expressed as [22]

$$
x \mathrm{In}_{2} \mathrm{O}_{3}+x \mathrm{Sn}^{4+} \longrightarrow \mathrm{In}_{2-x}^{3+}\left(\mathrm{Sn}^{4+} \cdot \mathrm{e}\right)_{x} \mathrm{O}_{3}+x \operatorname{In}^{3+} \text {. }
$$

The conductivity of the ITO thin films is affected by two major factors. One is the grain boundary scattering, and another is the ionized impurity centers scattering [19]. 


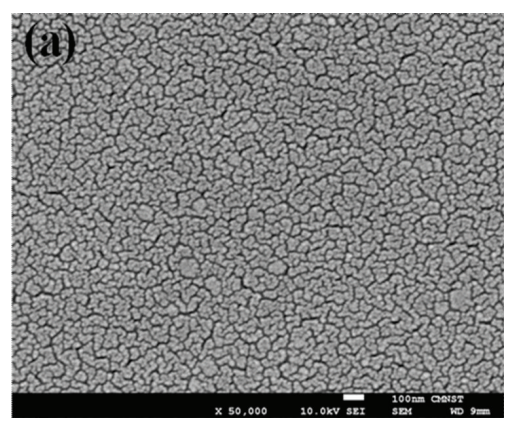

(a)

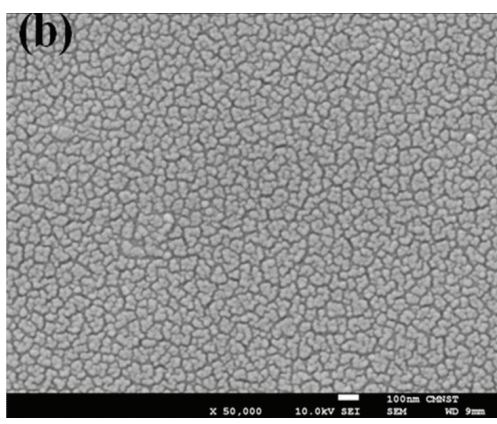

(b)

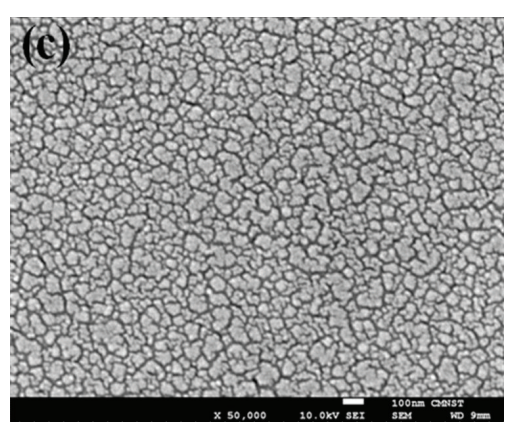

(c)

FIgURE 5: AFM surface views of the ITO thin films treated (a) without annealing and with annealing at (b) $400^{\circ} \mathrm{C}$ and $(\mathrm{c}) 600^{\circ} \mathrm{C}$ in $3 \%$ $\mathrm{H}_{2} / 97 \% \mathrm{~N}_{2}$ mixtures atmosphere.

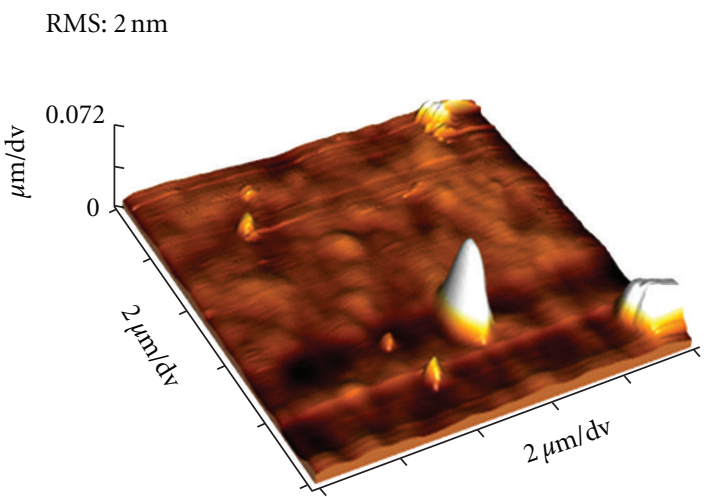

(a)

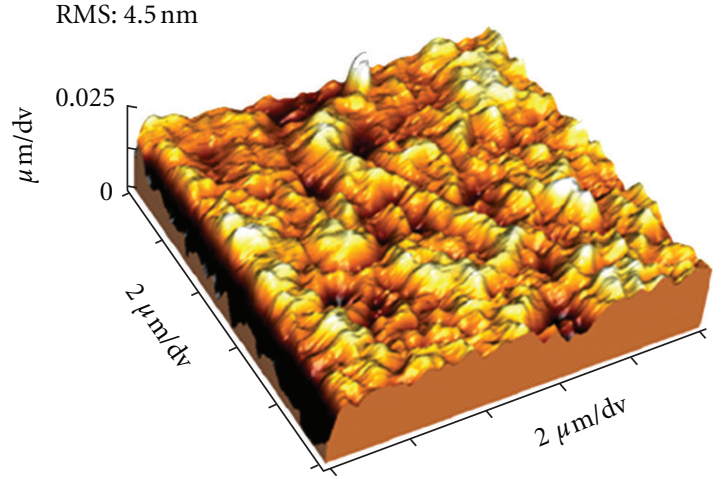

(b)

RMS: $4.8 \mathrm{~nm}$

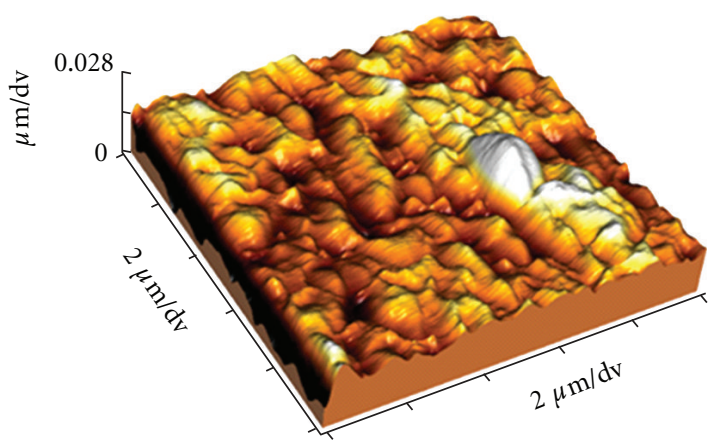

(c)

Figure 6: SEM images of the ITO thin films treated (a) without annealing and with annealing at (b) $400^{\circ} \mathrm{C}$ and (c) $600^{\circ} \mathrm{C}$ in $3 \% \mathrm{H}_{2} / 97 \% \mathrm{~N}_{2}$ mixtures atmosphere.

The grain size gradually increases the proportion of wellordered crystalline structures. Large grain size reduces the grain boundary scattering and enables the electron carriers to conduct smoothly. However, the ionized impurity centers served as the most important factor of the carrier concentration. The oxygen ion attracted by the doped ionized could be incorporated in lattice and segregated from the grain boundary, resulting in the distortion of the lattice and the generation of a neutral electron scattering center. As discussed in the Figures 4 and 6, the low conductivity of the prepared ITO films may be attributed to the undense film growth and the residual organic compounds, affecting the transportation of the carriers. The best resistivity is $5 \times 10^{-2} \Omega$-cm obtained for the ITO film with an annealing temperature of $600^{\circ} \mathrm{C}$ owing to the mechanisms of the considerable porosity $[8,11,23]$. 


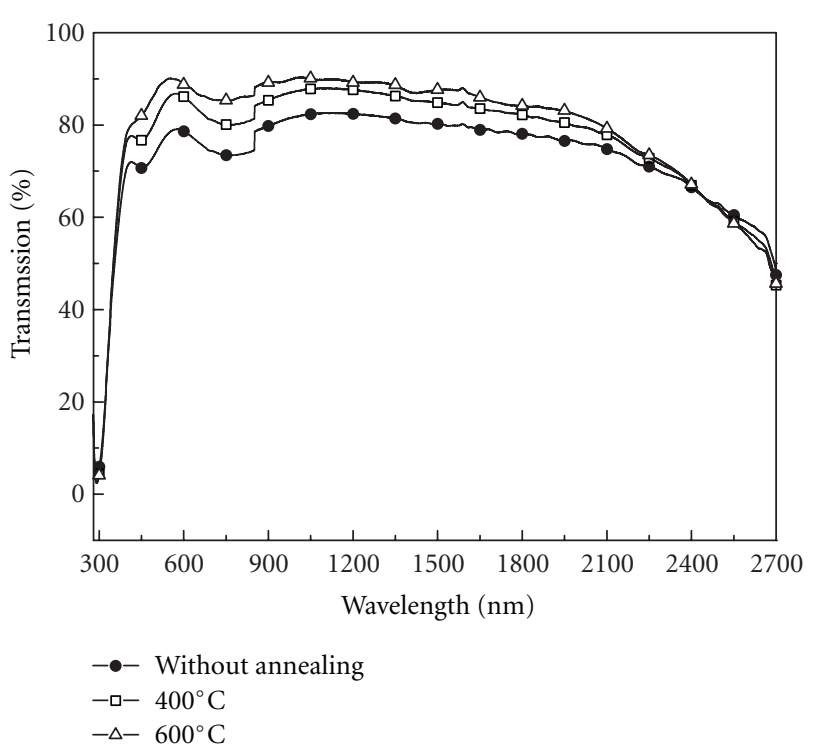

Figure 7: Optical transmittance spectra of the ITO thin films treated without annealing and with annealing at $400^{\circ} \mathrm{C}$ and $600^{\circ} \mathrm{C}$ in $3 \% \mathrm{H}_{2} / 97 \% \mathrm{~N}_{2}$ mixtures atmosphere.

\section{Conclusion}

In this paper, the ITO thin films were synthesized onto the glass substrates by a sol-gel process using a dip-coating method. A strong dependence of microstructure, crystal quality, electrical, and optical properties under annealing treatment conditions was found. The XRD results showed the prepared ITO thin films were cubic $\operatorname{In}_{2} \mathrm{O}_{3}$ structure and the calculated crystal sizes were around $3.3 \mathrm{~nm}$ to $4.5 \mathrm{~nm}$. The FTIR results showed the organic compounds could not be removed completely even when the postannealing temperature was operated at $600^{\circ} \mathrm{C}$. The SEM images indicated the prepared ITO thin films were not dense. The AFM results showed the RMS roughness was increased with the increased annealing temperature due to crystal growth. Moreover, the maximum transmittance in the visible range $(380-780 \mathrm{~nm})$ of $85.6 \%$ and the best resistivity is $5 \times 10^{-2} \Omega$ $\mathrm{cm}$ (namely, conductivity is $2 \times 10^{1} \mathrm{~S} / \mathrm{cm}$ ) were obtained for the ITO film treated with the annealing temperature of $600^{\circ} \mathrm{C}$. It is verified that the electrical properties of the prepared ITO films are strongly related to the microstructure variation, especially resulted from the un-dense film growth and un-removed organic compounds of the precursors.

\section{Acknowledgment}

The authors would like to acknowledge funding support from the Ministry of Education of Taiwan under Grant 98E06-087 and from the Nation Science Council of Taiwan, under Grant NSC 98-2221-E-020-017 and would also like to acknowledge Nanmat Technology of Taiwan for supporting the materials.

\section{References}

[1] P. K. Manoj, B. Joseph, V. K. Vaidyan, and D. S. D. Amma, "Preparation and characterization of indium-doped tin oxide thin films," Ceramics International, vol. 33, no. 2, pp. 273-278, 2007.

[2] R. Pan, S. Qiang, K. Liew, Y. Zhao, R. Wang, and J. Zhu, "Effect of stabilizer on synthesis of indium tin oxide nanoparticles," Powder Technology, vol. 189, no. 1, pp. 126-129, 2009.

[3] Y. C. Liang, "Surface morphology and conductivity of zirconium-doped nanostructured indium oxide films with various crystallographic features," Ceramics International, vol. 36, no. 5, pp. 1743-1747, 2010.

[4] O. Warschkow, D. E. Ellis, G. B. González, and T. O. Mason, "Defect structures of tin-doped indium oxide," Journal of the American Ceramic Society, vol. 86, no. 10, pp. 1700-1706, 2003.

[5] M. J. Alam and D. C. Cameron, "Investigation of annealing effects on sol-gel deposited indium tin oxide thin films in different atmospheres," Thin Solid Films, vol. 420-421, pp. 7682, 2002.

[6] M. Quaas, H. Steffen, R. Hippler, and H. Wulff, "Influence of microstructure on oxygen diffusion in plasma-deposited In/Sn films," Thin Solid Films, vol. 420-421, pp. 306-311, 2002.

[7] E. S. Raj and K. L. Choy, "Microstructure and properties of indium tin oxide films produced by electrostatic spray assisted vapour deposition process," Materials Chemistry and Physics, vol. 82, no. 2, pp. 489-492, 2003.

[8] A. Solieman and M. A. Aegerter, "Modeling of optical and electrical properties of $\mathrm{In}_{2} \mathrm{O}_{3}$ : $\mathrm{Sn}$ coatings made by various techniques," Thin Solid Films, vol. 502, no. 1-2, pp. 205-211, 2006.

[9] E. Celik, U. Aybarc, M. F. Ebeoglugil, I. Birlik, and O. Culha, "ITO films on glass substrate by sol-gel technique: synthesis, characterization and optical properties," Journal of Sol-Gel Science and Technology, vol. 50, no. 3, pp. 337-347, 2009.

[10] Z. H. Li, Y. P. Ke, and D. Y. Ren, "Effects of heat treatment on morphological, optical and electrical properties of ITO films by sol-gel technique," Transactions of Nonferrous Metals Society of China, vol. 18, no. 2, pp. 366-371, 2008.

[11] T. S. Renuga Devi and S. Gayathri, "FTIR and FT-Raman spectral analysis of paclitaxel drugs," International Journal of Pharmaceutical Sciences Review and Research, vol. 2, no. 2, pp. 106-110, 2010.

[12] I. Hamberg and C. G. Granqvist, "Evaporated Sn-doped $\operatorname{In}_{2} \mathrm{O}_{3}$ films: basic optical properties and applications to energyefficient windows," Journal of Applied Physics, vol. 60, no. 11, pp. R123-R159, 1986.

[13] S. R. Ramanan, "Dip coated ITO thin-films through sol-gel process using metal salts," Thin Solid Films, vol. 389, no. 1-2, pp. 207-212, 2001.

[14] S. S. Kim, S. Y. Choi, C. G. Park, and H. W. Jin, "Transparent conductive ITO thin films through the sol-gel process using metal salts," Thin Solid Films, vol. 347, no. 1-2, pp. 155-160, 1999.

[15] L. Yang, X. He, and F. He, "ITO coated quartz fibers for heat radiative applications," Materials Letters, vol. 62, no. 30, pp. 4539-4541, 2008.

[16] B. L. Zhu, X. H. Sun, S. Guo et al., "Effect of thickness on the structure and properties of $\mathrm{ZnO}$ thin films prepared by pulsed laser deposition," Japanese Journal of Applied Physics, vol. 45, no. 10, pp. 7860-7865, 2006. 
[17] A. Solieman and M. A. Aegerter, "Modeling of optical and electrical properties of $\operatorname{In}_{2} \mathrm{O}_{3}$ : Sn coatings made by various techniques," Thin Solid Films, vol. 502, no. 1-2, pp. 205-211, 2006.

[18] E. Çetinörgü, S. Goldsmith, and R. L. Boxman, "The effect of annealing on filtered vacuum arc deposited $\mathrm{ZnO}$ thin films," Surface and Coatings Technology, vol. 201, no. 16-17, pp. 72667272, 2007.

[19] J. Liu, D. Wu, and S. Zeng, "Influence of temperature and layers on the characterization of ITO films," Journal of Materials Processing Technology, vol. 209, no. 8, pp. 3943-3948, 2009.

[20] S. Y. Chu, W. Water, and J. T. Liaw, "Influence of postdeposition annealing on the properties of $\mathrm{ZnO}$ films prepared by RF magnetron sputtering," Journal of the European Ceramic Society, vol. 23, no. 10, pp. 1593-1598, 2003.

[21] J. A. Thornton, "High rate thick film growth," Annual Review of Materials Research, vol. 7, pp. 239-260, 1977.

[22] Z. H. Li and D. Y. Ren, "Fabrication and structure characterization of ITO transparent conducting film by sol-gel technique," Transactions of Nonferrous Metals Society of China, vol. 17, no. 3, pp. 665-668, 2007.

[23] L. Yang, X. He, D. Ge, and H. Wei, "Densification study of ITO films during high temperature annealing by GISAXS," Physica $B$, vol. 404, no. 16, pp. 2146-2150, 2009. 

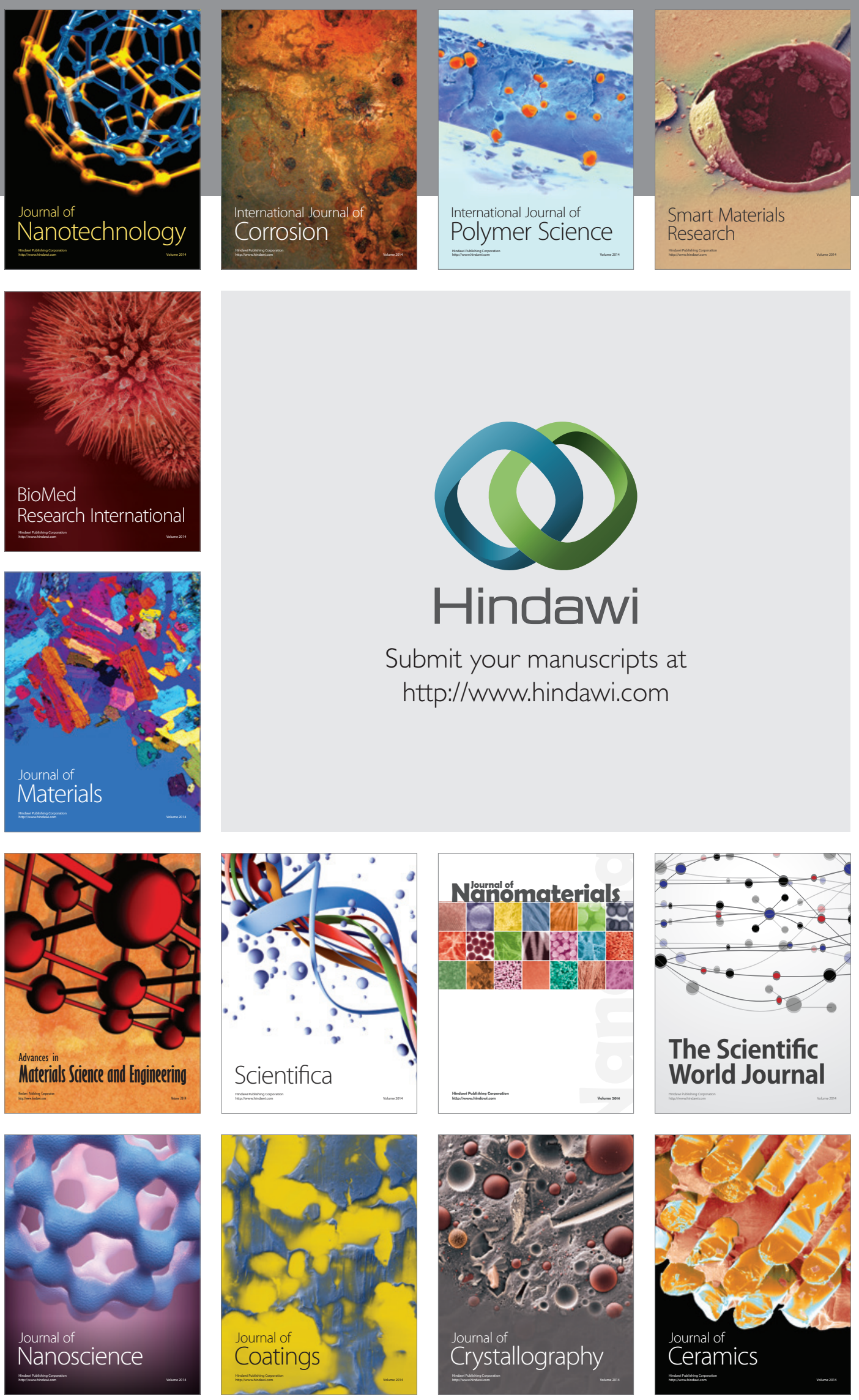

The Scientific World Journal

Submit your manuscripts at

http://www.hindawi.com

\section{World Journal}

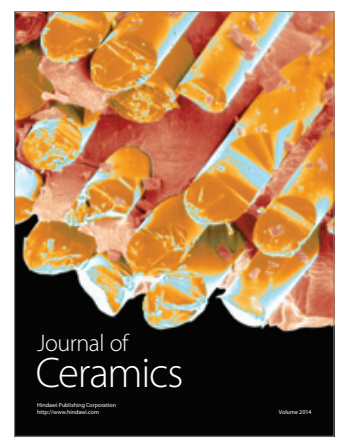

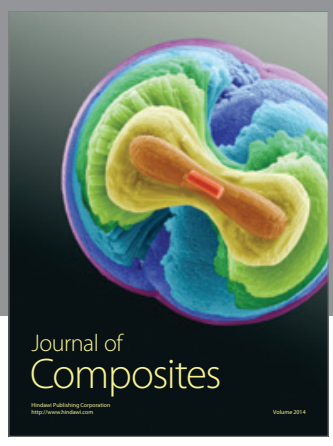
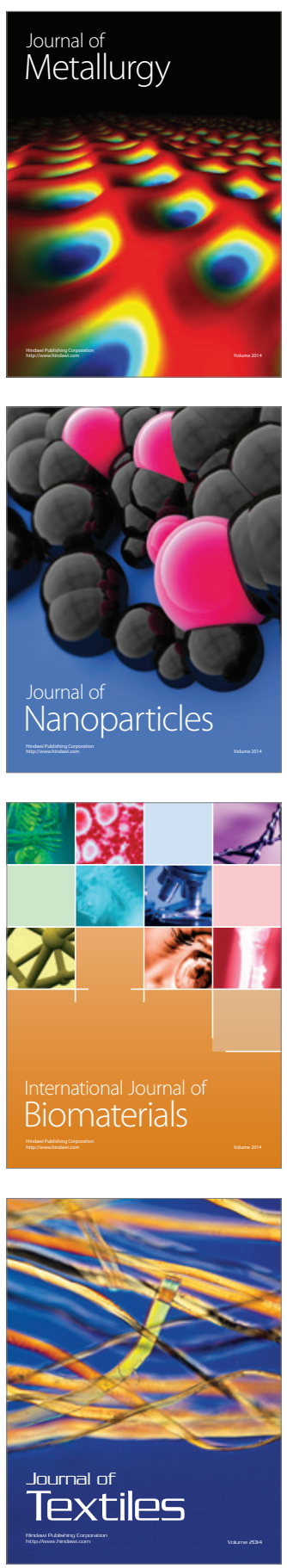